\title{
The Design on Dance Teaching Mode of Personalized and Diversified in the Context of Internet
}

\author{
Rong $\mathrm{Mao}^{1, *}$ \\ ${ }^{1}$ School of Music, Liaoning Normal University, Dalian Liaoning, China
}

\begin{abstract}
Traditional dance teaching emphasizes the consistency model and lacks the exploration of students' individual characteristics. However, individualized and diversified dance education is a diversified dance talent cultivation oriented to different objects and objectives according to the differences of students' natural conditions, educational background and development needs. Due to the single and real-time traditional dance teaching mode, there are limitations in the realization of multi-attribute and multi-objective dance talent training. This paper establishes a dance teaching situation with the function of network interaction, and solves the difficulties in individualized and diversified dance teaching. The research shows that the integration of online and offline education mode not only has certain theoretical value in teaching, but also has great practical significance for the cultivation of personalized and diversified dance talents.
\end{abstract}

\section{INTRODUCTION}

The comprehensive development and implementation of the national quality education policy in the new era is the basis of the dance education reform and curriculum construction. In the past 70 years, China's dance education has been closely following the party's policies and the development of the country, opening up a new historical period of dance education. General Secretary Xi Jinping stressed at the national education conference: "we should comprehensively strengthen and improve aesthetic education in schools, adhere to aesthetic education, cultural education, improve students' aesthetic and humanistic quality. As an important part of aesthetic education in China, dance education not only enlightens people's minds, but also influences the lifestyle and attitude of the educated. The world famous dance educator Ted Shawn (1891 - 1972) once said, "I think the real dance education is the comprehensive education of a person -- his body, mind and emotions will be nourished, nurtured and exercised in the dance. It can be seen that dance education has a high demand on the comprehensive quality of educators, and only when the professional quality of teachers and the dance of quality education complement each other, can it adapt to the comprehensive development of aesthetic education. In the face of the national quality-oriented education policy and the new requirements of aesthetic education, the development trend of dance education in the future is to pay attention to individualized teaching and cultivate diversified innovative talents in dance. However, the traditional dance teaching mode, which is single and real-time, has its limitations in the realization of mufti-attribute and mufti-objective cultivation of dance talents. The purpose of this study is to solve the difficulty of achieving individuation and diversification in dance teaching by establishing a teaching system model integrating online and offline. The main innovation point is to put forward the network teaching mode which conforms to the characteristics of dance education.

\section{Personalized dance education}

\subsection{The connotation of personalized dance education}

The outline of the national medium - and long-term plan for education reform and development (2010-2020) (hereinafter referred to as the outline of the education plan) states that "we should care about every student, promote every student's active and lively development, respect the law of education and the law of students' physical and mental development, and provide suitable education for every student". The introduction of the outline of educational planning promoted dance educators to pay attention to personalized education on the basis of students and on the premise of individual differences among students. Gu Mingyuan believes that personalized education is to cultivate the development of students' personality [1]. The research shows that: dance personalized education is based on students' natural conditions, educational background, development needs and other aspects of the differences, for each student to provide a variety of independent career choice, give full play to the potential of individual advantages of students, to build an education platform suitable for their personality development. The transformation of dance 
education from the traditional teaching mode of "imitation, reproduction, unity and identity" to the "individualized teaching mode with the premise of respecting the individual differences of educates and the purpose of promoting the all-round development of educates".

\subsection{The Problems that Should be Paid Attention to in Personalized Dance Education}

Ancient Greek philosopher Plato advocated "gift ideas", said: "the potential, deep inside the person's individual talent for talents each person is different, formed the unique individual character difference, so for endowment characteristics of different people, take appropriate education methods and means, developing different expertise and professional tend to be particularly important," [2]. Plato's idea of "innate talent" is also our understanding of personalized education of dance. The following problems should be paid attention to in individualized dance education:

\section{1) Learning and application of knowledge}

Personalized dance teaching aims at transferring professional theories and knowledge and skills to all students, mastering dance body language and creation technology, and expressing and reflecting on each student's own acceptance ability and comprehensive application ability, so as to form their relatively broad thinking ability and application ability. In particular, teachers should be good at analyzing, reflecting and regulating the individual differences in students' "core knowledge understanding" and "application of new knowledge from one example to another", look at the reasons of students' receptivity from multiple perspectives, and timely solve students' negative emotions and ideological burden. Thus arouses the student's study enthusiasm and the interest, causes the student to obtain the knowledge and the skill in the happiness, and achieves the teaching and the study the harmonious unification.

\section{2) Improving teaching philosophy}

The teaching idea of "taking students' learning as the foundation". Follow the law of dance education and the law of students' physical and mental growth, pay attention to the development of each student's advantage potential, so that students from the lack of subjective initiative "extensive development" to "people-oriented" active "connotation development" transformation. From the cultivation of unitary knowledge and skills to the cultivation of multi - dance, multi - ability, multi accomplishment and personality. Inspire and guide students to open the initiative learning thinking, thinking and discovery, questioning and creation, conversation and discussion and other forms of methods, fully mobilize the imagination and association of each student. Every student can take the initiative to experience the aesthetic standards and spiritual pursuit of different dance styles through their own body and mind [3]. Systematically master the style, language, technical ability and relevant theoretical knowledge of each dance, and complete the expression of practical technology and theoretical connotation based on image thinking and with logical thinking as the ultimate goal, so as to expand and enrich the multiple channels for them to acquire knowledge.

\section{3) Improve the quality of teachers}

As the organizer and implementers of teaching activities, teachers play a leading role in the process of student cultivation [4]. The improvement of teachers' own quality is the premise of developing personalized dance teaching and cultivating diversified and innovative talents. Dance students because of its professional features smaller than other specialized student age, world outlook, the outlook on life, values still in the early stage of development, university undergraduate course education for students dance is not only the cultivation of knowledge and ability, but also in their emotion, attitude, will, values, etc., to form good personality quality and the important stages of moral sentiment. Therefore, teachers should always keep the concept of lifelong development, keep learning, pay attention to professional growth, carry out lifelong education for students, and build the target direction suitable for students' further study and development with extensive knowledge and experience.

4) Social demand-oriented practice and practice teaching activities

College education is a ladder for students to step into the society. Students need to face the society positively and accept the challenges bravely. There is a great demand for dance talents in various fields in our society, especially in large and medium-sized cultural and artistic activities in enterprises and institutions, dance competitions in colleges and middle schools, quality dance education, and social training institutions. However, there are few jobs in the job market, and the channel of job market is narrow. Take 2016 dance major students of capital normal university as an example, there are 36 fresh graduates, 35 of whom have decided to graduate, and the overall employment rate is $97 \%$, among which 4 (11\%) have signed employment agreements and labor contracts, $9(26 \%)$ have signed employment contracts, and $22(63 \%)$ have freelance jobs [5]. Most of the students are employed by themselves in the society, and the employment direction of students is diversified, which puts forward higher requirements for dance education. During the school period to provide students with diversified practice, internship opportunities, strengthen practice education. Let students explore the platform suitable for personal development in practice, improve the effect of practice, and implement personalized dance education.

\section{Diversified DANCE EDUCATION MODE}

Personalized dance education is an education that combines the all-round development of dancing talents with the individualized training. The purpose is to enhance the diversified creativity of students to meet the needs of the socialization process.

\subsection{The meaning of Dance Diversity}

The research shows that the cultivation of diversified innovative dance talents refers to the construction of multi-dance, multi-accomplishment and multi-ability as 
the knowledge goal, with the ultimate goal of cultivating students' innovation consciousness and developing educates' creative thinking.

\section{1) Multi-dance}

Multi-dance refers to that students not only master a certain dance (ethnic, classical, ballet, modern), a certain gender of the dance, but also not only boys learn boys, girls learn girls dance, to learn widely different gender, different dance vocabulary and technical skills, to understand the aesthetic standards and spiritual pursuit of different dance styles. Systematically master the languages and techniques of Chinese classical dance, Chinese ethnic dance (dance of the five major ethnic groups and ethnic minorities), ballet, modern dance, jazz dance, etc., and flexibly use the styles and languages of multiple dances for performance, teaching, creation, etc., so as to improve the professional and comprehensive quality of the educates [6].

\section{2) Many literacy}

Multi-accomplishment refers to humanistic accomplishment, professional accomplishment, theoretical accomplishment and so on. The accumulation and improvement of literacy can lead to the aesthetic thinking of culture and art, and make image thinking and logic thinking interweave and parallel. The individualized teaching effect can be reflected in personality quality and culture and art, professional knowledge and theoretical level, ideological and political education and logical speculation.

\section{3) Multiple abilities}

Multiple abilities refer to the ability of dance education and teaching, stage performance, choreography, scientific research and practical application. Some people believe that students with poor dance skills are engaged in dance education, but this is not the case. Compared with dancers, choreographers and dance theorists, dance teachers should be the most comprehensive and advanced talent field. Dance educators have the comprehensive ability to educate people from the perspective of philosophy, apply textbooks from the perspective of science, create from the perspective of innovation, arrange and combine, organize, coordinate and manage, etc., which determines the width, breadth and height of their graduation exit [7].

\section{4) More knowledge}

Besides mastering professional skills and theoretical knowledge of dance, teachers also need to learn knowledge of pedagogy, psychology, interdisciplinary and other aspects. The connotation accumulation of teachers' multi-ability, multi-knowledge and multiaccomplishment will bring up the good formation of teenagers' personality and artistic taste in the new era. The cultivation of students' multi-accomplishment, multiknowledge and multi-ability should be emphasized under the individualized dance education. Constantly strengthen the students' imagination, creativity and aesthetic appreciation.

\subsection{Reasonable Configuration of Courses}

The cultivation of diversified and innovative talents should face up to the "challenges of The Times", actively promote the construction of dance courses, and solve the reasonable allocation of training programs, graduation requirements and curriculum. One is to adjust the distance between the quality of the main body of teaching and the goal of training. The second is to optimize the curriculum, professional compulsory courses "to complete and refined, teaching effect [8]. In addition, relying on the resources and environmental advantages of comprehensive humanities, the university will strengthen crossdisciplinary and interdisciplinary exchanges and communication with other colleges and expand the proportion of elective courses. The third is to adjust the relationship between social needs, training objectives and teaching content. In view of the above course configuration, the dance education curriculum is formulated, which is embodied in the three aspects of the curriculum [9].

Firstly, from the perspective of dance art, we should comprehensively learn ballet, Chinese classical dance, folk dance, modern dance and other relatively systematic professional courses.

Secondly, to master pedagogy, psychology, dance teaching method, dance pedagogy and other courses.

Thirdly, it is necessary to comprehensively master dance history and dance-related elective courses, as well as lighting choreography, piano, vocal music and dance anatomy.

\section{THE DESIGN OF NETWORK INTERACTIVE TEACHING MODE}

\subsection{Current Situation of Dance Teaching Mode}

In the traditional dance teaching process, teachers' teaching and demonstration are the main, students are in the passive imitation, to reach the prescribed standards through repeated practice. This way ignores the students' own feelings, lacks the expression of personality and enthusiasm from the students' perspective, and this kind of classroom teaching lacks aesthetic consciousness.

"Internet + education" is changing the traditional teaching mode and promoting the reform of dance teaching mode. However, the teaching mode of dance is "teaching by words and deeds", which is related to its special teaching method. The existing teaching mode is that the teacher does the demonstration, the students learn and imitate the teacher's movements, if the teacher does not do the demonstration and correct the students' irregular movements, the students will be difficult to learn the technical essentials of dance, and this is the difference between dance teaching and other disciplines teaching. Although this kind of traditional format teaching can directly achieve the teaching purpose, it neglects to stimulate the spontaneity and creativity of students in the learning process, as well as the cultivation of their artistic inspiration [10]. 


\subsection{The significance and function of "Internet +" dance teaching mode}

With the rapid development of the Internet, dance teaching has also ushered in opportunities and challenges in the Internet era. How to use the Internet technology to improve the dance teaching model and how to promote the development of dance education is the responsibility and obligation of dance teachers.

Firstly, network teaching is conducive to promoting the personalized characteristics of students. With the help of Internet technology, the students' learning information system is established to observe the students' basic situation at any time, so as to master the students' learning situation, so as to better start the dance teaching work.

Secondly, network teaching is beneficial to students' self-study. If students have no firm memory of the dance movements taught by the teacher in class, they can search the contents taught by the teacher on the Internet after class, which is not limited by space and time, and provides greater convenience for students' learning autonomy.

Thirdly, network teaching is beneficial to the automation of teaching management. With the support of Internet technology, teachers and students can only impart and receive knowledge in the classroom, increase the interaction between teachers and students, more conducive to the management and deepening of the relationship between teachers and students.

Fourth, network teaching is conducive to the innovation of teaching content. The Internet has changed the track of development and the way of connection of things. "Internet + " dance teaching can not only update the teaching concept and teaching ideas, but also update the teaching method with the help of new media, enrich the teaching content, and provide students with updated course content.

\section{3 "Internet +" dance teaching mode design}

\section{1) Network teaching platform based on man-machine interaction}

Dance courses in normal universities can be taught in a variety of ways. For example, by setting up douyin accounts and WeChat public accounts, teachers can place their works on we-media platforms for students and even denizens to watch and study, so as to improve students' learning fun. On the other hand, teachers can also watch the works uploaded by others and update their own teaching content. At the same time, students are encouraged to upload their works to we media platform to improve their confidence in learning. Figure 1 shows the basic framework of interactive dance teaching system based on network.

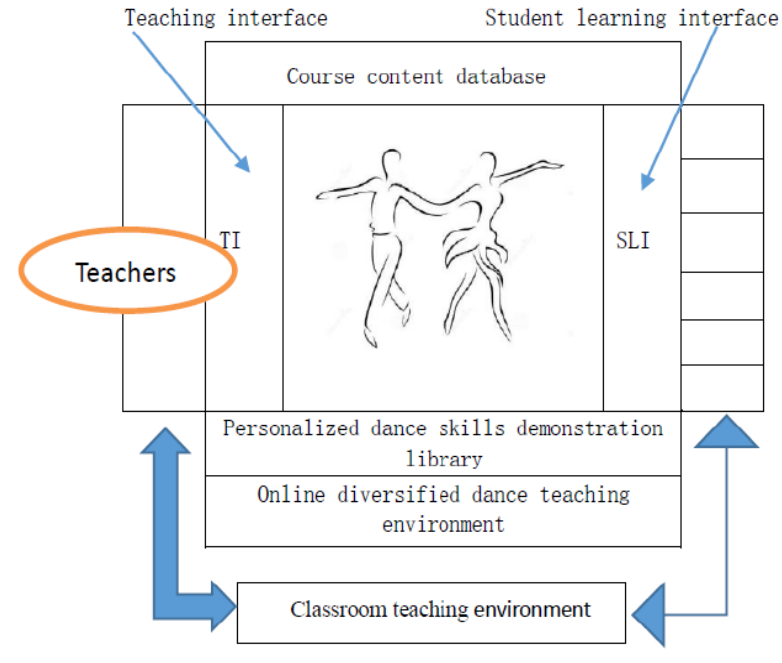

Figure 1. The basic framework of interactive dance teaching system based on network

\section{2) Update the classroom teaching mode}

With the support of Internet technology, teachers can upload their lectures in advance, so that students can watch and comprehend them before class, and then discuss with teachers in class. This can update the previous "cramming" teaching methods, so as to achieve better teaching purposes and improve the quality of learning.

3) Enrich the classroom teaching content

The dance teaching network platform based on the background of "Internet + " enriches the dance teaching content. Dance teachers should not only learn to use Internet resources, but also teach basic courses. In addition, dance teachers should also extensively absorb relevant excellent dance resources at home and abroad according to the characteristics of their own colleges and universities to create excellent courses.

\section{Conclusions}

To sum up, personalized education is the basis for cultivating innovative talents, and the purpose of personalized education is to continuously strengthen the personalized education of dance and cultivate students' diversified innovation ability. Personalized dance education allows the existence of different personalities, design different plans for different students, respect and care for talents with different personalities. The traditional teaching mode has its limitations in the process of personalized dance education. This paper establishes an internet-based dance teaching mode with diversified teaching management functions, which can achieve personalized and diversified dance teaching objectives and provide an effective research path for the reform and innovation of dance education.

\section{RefERENCES}

1. $\mathrm{Gu}$ Mingyuan. Innovation of individualized education and talent cultivation mode. Journal of 
The Chinese Society of Education, 2011, vol.19, pp.5-8.(Chinese)

2. Song Guandong, Wang Sihui. Reflection on Individuality Education Reform in Higher Education Institutions. Modern educational management, 2014, vol.10, pp.54-57. (Chinese)

3. Deng Youling, Jin Hao, Blue book on the development of dance higher education. China Minzu University Press, 2018. (Chinese)

4. Yang Jinli. A study on the cultivation and employment strategy of dance major in colleges and universities. Home Drama, 2018, vol.14, pp.167. (Chinese)

5. Meng Juan, Peng Yunshi. Practice of humanistic psychology: enlightening potential education theory. Educational research and experimentation, 2008, vol., pp.58-61. (Chinese)

6. Li Xiaoli. To develop primary school teachers' quality under the background of students' core quality. Quality education in western China, 2019, vol. pp.114-115. (Chinese)

7. Mao Rong. The influence of the artistic view of the integration of culture and art on the cultivation of dance talents. Home Drama, 2019, vol.12, pp.136137. (Chinese)

8. Li Yang. Diversified dance education and its methods. Education, 2015, vol.7, pp.36. (Chinese)

9. Hou Lijuan. The development of diversified social dance. Music time and space, 2016, vol.3, pp.86-87. (Chinese)

10. Dong Yinghong, Liu Wei, Li Fentian. Research and practice of diversified teaching mode based on Internet + . Jilin Education, 2018, vol.8, pp.31-32. (Chinese) 